\title{
Investigation of the impact of Antarctic ice-shelf melting in a global ice-ocean model (ORCA2-LIM)
}

\author{
Caixin WANG, Aike BECKMANN \\ Division of Geophysics, University of Helsinki, PO Box 64, FIN-00014 Helsinki, Finland \\ E-mail: caixin.wang@helsinki.fi
}

\begin{abstract}
Ice-shelf melting (ISM) removes heat from and injects fresh water into the adjacent ocean and contributes significantly to the freshwater balance and water mass formation in the Antarctic marginal seas. The thermodynamic interaction between ocean and ice shelf is a complicated process and usually not adequately included in the ocean-ice climate models. In this paper, the ISM from all major ice-shelf areas around Antarctica is added to a global coupled ice-ocean model ORCA2-LIM following the parameterization proposed by Beckmann and Goosse (2003). Using interannual forcing data from 1958 through 2000, the impact of ISM on Southern Ocean hydrography and sea-ice distribution is investigated. The model also shows global signatures of the Antarctic ISM.
\end{abstract}

\section{INTRODUCTION}

The freezing and melting of sea ice in the Southern Ocean influences the formation of deep and bottom water masses in the Antarctic marginal seas, and ultimately also the global thermohaline circulation. Ice shelves in Antarctica represent about $44 \%$ of the coastline surrounding the Antarctic ice sheet (Drewry, 1983) and constitute a major factor for the changes in the Southern Ocean. Every year a large number of icebergs of various sizes calve from ice shelves and glacier tongues. The meltwater injection into the Southern Ocean has been modeled by Gladstone and others (2001). However, this contribution to the freshwater budget has large temporal and spatial variability. In contrast, the influence of ice-shelf melting (ISM) is continuous, due to perpetually removing heat from and adding fresh water into the adjacent ocean. Hence, it plays a role of similar importance to that of sea ice not only in the freshwater balance (e.g. Timmermann and others, 2001) but also in the water mass formation (Hellmer, 2004) in the Antarctic marginal seas. Omission of ISM causes too warm highsalinity shelf water, a weaker horizontal circulation and an increased probability for open-ocean convection in the Weddell Sea (Beckmann and others, 1999).

Modelling of the thermodynamic exchange between ocean and ice shelves requires the inclusion of ice-shelf cavities in the model configuration. However, Beckmann and Goosse (2003) have suggested that parameterization without explicitly including the ice-shelf cavities might be possible. They assumed that the heat loss $\left(Q_{\text {net }}\right)$ and freshwater gain due to the ISM is proportional to (i) the temperature difference between the ocean outside of the cavity at 200$600 \mathrm{~m}$ depth $\left(T_{\text {ocean }}\right)$ and the in situ freezing point at the base of the ice shelf $\left(T_{\mathrm{f}}\right)$; and (ii) a constant 'penetration length $L_{\text {eff }}$ into the cavity. The net heat flux at the ice-shelf base,

$$
Q_{\text {net }}=\iint \rho_{\mathrm{w}} C_{\mathrm{pw}} \gamma_{\mathrm{T}}\left(T_{\text {ocean }}-T_{\mathrm{f}}\right) \mathrm{d} x \mathrm{~d} y,
$$

is simplified to

$$
Q_{\text {net }}=\rho_{\mathrm{w}} C_{\mathrm{pw}} \gamma_{\mathrm{T}}\left(T_{\text {ocean }}-T_{\mathrm{f}}\right) L_{\mathrm{eff}} W,
$$

where $W$ is the along-shelf width. (For further details of the approach, the reader is referred to Beckmann and Goosse, 2003.) This parameterization is implemented into a global ice-ocean model to investigate the impact of ISM. However, we should keep in mind that the parameterization is only a crude way to include the ISM; both over- and underestimations of the effects are possible, but ignoring the contribution from ISM is even less acceptable.

\section{MODEL CONFIGURATION}

The model applied in this study is the coupled global iceocean model ORCA2-LIM with a zonal resolution of $2^{\circ}$ and changing meridian resolution of $2^{\circ} \times \cos \phi$ decreasing to $0.5^{\circ}$ near the equator. The ocean model is a finite-difference global ocean general circulation model with a free sea surface and non-linear equation of state. It is coupled to a dynamic-thermodynamic sea-ice model. Configuration, parameter settings and forcing are largely similar to those described in Timmermann and others (2005). Exceptions are: we use (a) monthly mean hydrographic fields from the Levitus and others (1999) dataset for initialization and restoring; (b) the interannual daily CORE (Coordinated Ocean Reference Experiments) forcing data from 1958 through 2000 (Large and Yeager, 2004); (c) a turning angle of $-15^{\circ}$ between sea ice and water; (d) a weaker restoring sea surface salinity with a timescale of 292 days to avoid the climatic drift and spurious open-ocean convection in the Weddell Sea (Timmermann and others, 2005); and (e) the ISM parameterization added in the ISP case below, with a penetration length $L_{\text {eff }}=10 \mathrm{~km}$ chosen to lead to more realistic Antarctic Circumpolar Current (ACC) transport through Drake Passage (see below).

All major Antarctic ice shelves are included in the model (see Fig. 1). The location of ice-shelf-ocean interaction is set next to the continent or, in the case of the Weddell and Ross Seas, to the model boundary. Two experiments were performed: a reference case without ('REF') and one with the ISM parameterization ('ISP'). Two passes of the 43 year forcing cycle were integrated; results of the second pass are shown below if not mentioned.

\section{MODEL RESULTS}

After adding the ISM, the increasing trend of ACC transport through Drake Passage in the first pass is effectively suppressed to be a more steady state. Its mean magnitude 
changes from $180 \mathrm{~Sv}$ to $150 \mathrm{~Sv}$ in the second pass, which compares more realistically to the observation of $134 \mathrm{~Sv}$ although still somewhat higher. In the following, the ISMinduced changes in Southern Ocean hydrography, sea-ice distribution and global fields are analyzed.

\section{ISM effects on Southern Ocean hydrography}

Due to the additional freshwater input, adding ISM changes the restoring flux to $-1.17 \times 10^{-5} \mathrm{~kg} \mathrm{~m}^{-2} \mathrm{~s}^{-1}$ (in ISP) from $-1.45 \times 10^{-5} \mathrm{~kg} \mathrm{~m}^{-2} \mathrm{~s}^{-1}$ (in REF). Responding to this adjustment, the volume-averaged annual mean salinity and potential temperature changes from $3.051^{\circ} \mathrm{C}$ and $34.74 \mathrm{psu}$ (practical salinity units) (for REF) to $3.141^{\circ} \mathrm{C}$ and $34.73 \mathrm{psu}$ (for ISP), respectively, which is much closer to the Levitus values of $3.167^{\circ} \mathrm{C}$ and $34.72 \mathrm{psu}$.

As expected, the water masses next to the continent become colder and fresher with ISM added (Fig. 2), but the changes in stability and circulation also lead to warming and increased salinity in other areas of the Antarctic marginal seas. Local differences exceeding $1^{\circ}$ and 0.5 psu are found in the immediate vicinity of the continent. Meanwhile, large tracer differences are also found in the ACC regions.

Melting 'hotspots' are found in the Amundsen and Bellingshausen Seas (where the ACC is relatively close to the continental shelf), in the West Ice Shelf area, in the northeastern Weddell Sea (Fimbul and Ekström Ice Shelves) and in the western Weddell Sea (an area of accumulation from both local and circumpolar remote melting regions). This pattern is similar to the results of Beckmann and others (1999) and Hellmer (2004) who included ice-shelf cavities explicitly in their models.

The upper-ocean vertical water mass structure has also changed significantly (Fig. 3), with warmer and more saline waters below $500 \mathrm{~m}$ throughout the Southern Ocean. Mixed-layer differences are most pronounced during summer, while seasonal subsurface differences are small next to the continent but significant in the tropics.

The overall good correspondence with previous modeling studies leads us to conclude that the applied ISM parameterization seems an adequate way to include this additional forcing in global ice-ocean climate models.



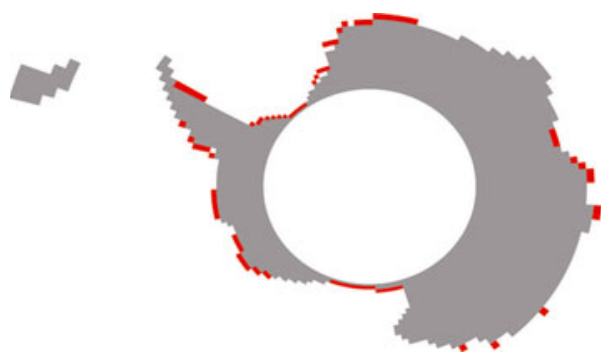

Fig. 1. Location of the included Antarctic ice shelves.

\section{ISM effects on sea-ice distribution}

The modeled sea-ice extent (the area with ice concentration $>15 \%$ ) in ISP and REF is shown in Figure 4. Overall, the REF results are very close to those obtained by Timmermann and others (2005), meaning that both model runs share the same deficiencies.

The inclusion of ISM leads to an increase of the sea-ice extent (Fig. 4a) by about $11 \%$ for the whole year. This is a clear improvement when compared to the observational data derived from the Special Sensor Microwave Radiometer (SSMR)-Special Sensor Microwave/Imager (SSMI/I) during October 1978-December 2003 (J. Comiso, http://nsidc.org: 80/data/nsidc-0002.html). Two other aspects, however, were not affected by the addition of ISM: the minimum sea-ice extent in January-February is still too low; and the maximum sea-ice extent still occurs 1 month too early, hence the seaice growth occurs faster than observed.

Further investigations are necessary to overcome these deficiencies (which might turn out to be a consequence of deficiencies in the forcing datasets).

Due to the cooling of the mixed layer and increase in the upper-ocean stratification, the 43 year time series of sea-ice extent (figure not shown) show again that including ISM leads to generally higher values. Time series of monthly anomalies (differences of monthly means from the climatology mean) are shown in Figure $4 \mathrm{~b}$. We do not find a significant difference in interannual variability due to the addition of ISM. During the last two decades of the simulation, the

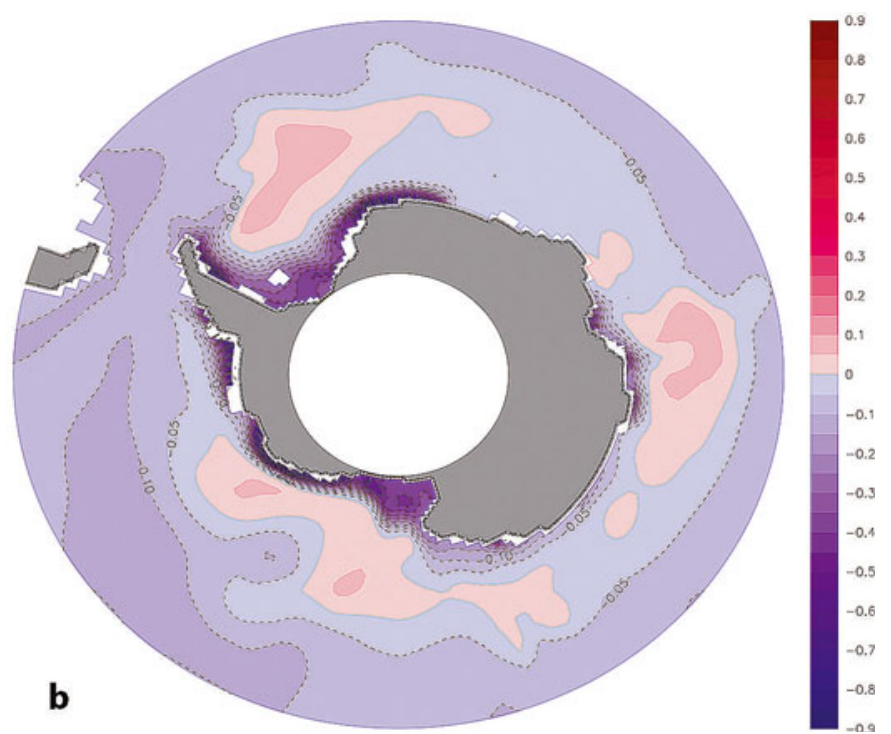

Fig. 2. Climatological mean differences (ISP-REF) of (a) temperature and (b) salinity at $216 \mathrm{~m}$ depth in the Southern Ocean. 



Fig. 3. Climatological seasonal mean (summer: January-March; winter: July-September) differences (ISP-REF) of (a) temperature and (b) salinity along a $30^{\circ} \mathrm{W}$ transect.

model captures the variability as seen from the satellite observations. The pronounced anomalies in 1980/81, 1986/ 87 and 1996/97 are especially well reproduced.

The changes brought about by adding the ISM are easily seen in the distribution of sea-ice variables. The equatorward edge of the sea-ice cover (Fig. 5a) is generally pushed northward, most notably in the Atlantic and Pacific sectors of the Southern Ocean. The coastal areas are largely unaffected, except for the Amery Ice Shelf region. In contrast, most changes of the mid-winter sea-ice thickness (Fig. 5b) can be found near the coast, again most pronounced $(>0.5 \mathrm{~m})$ on both sides of the Antarctic Peninsula. In the Weddell sector, the effect of the gyre-scale circulation in the sea-ice distribution is clearly seen.
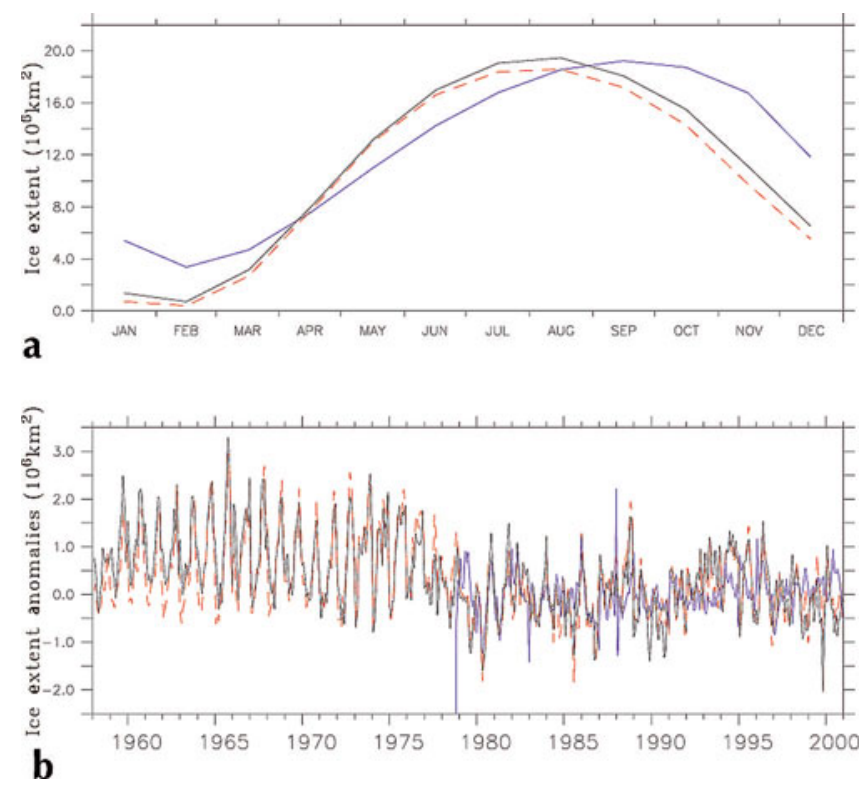

Fig. 4. (a) Climatological seasonal cycle of sea-ice extent, and (b) interannual variability of sea-ice extent: observation (blue line), ISP (black line) and REF (red line).
Our model predicts a larger thickening of the sea ice than Hellmer's (2004) model which obtained a maximum thickening of $0.2 \mathrm{~m}$, possibly because the freshwater input originating from the ice shelf is somewhat overestimated in our study. The sea ice thickens drastically close to the region of Amery, West and Shackleton Ice Shelves (Fig. 5b because West and Shackleton Ice Shelves add too much fresh water.

\section{ISM effects on global ocean}

In the previous subsections, we discussed the ISM effects on the Southern Ocean, and one might not be surprised at our findings. But how far does the influence of the Antarctic ISM reach? Are there systematic influences of Antarctic ISM in remote areas, and if so, in which direction?

To address these questions, Figure 6 shows the annual mean of mixed-layer depth (MLD) difference ISP-REF for the second integration pass. Including ISM leads to a deepening mixed layer in the coastal region of the Southern Ocean and, at the same time, a shallower MLD in Pacific and Atlantic sectors of the ACC.

The only other region where we find a pronounced change in MLD is the northern North Atlantic, along the Greenland-Iceland-Scotland ridge, a crucial region for European climate. A relatively large area shows systematic deepening of the mixed layers more than $40 \mathrm{~m}$. This teleconnection can be found in the second pass results, indicating that the timescale of signal transmission is $<40$ years.

Additional analyses are required to determine the physical mechanisms of this phenomenon, but it seems that changes in ISM around Antarctica are closely connected to changes in MLD in the northern North Atlantic.

\section{SUMMARY}

The ISM parameterization of Beckmann and Goosse (2003) has been implemented into the ORCA2-LIM model to investigate the effects of ISM. The study indicates that the additional source of cold and fresh subsurface water leads to significant rearrangements in the local hydrography and 

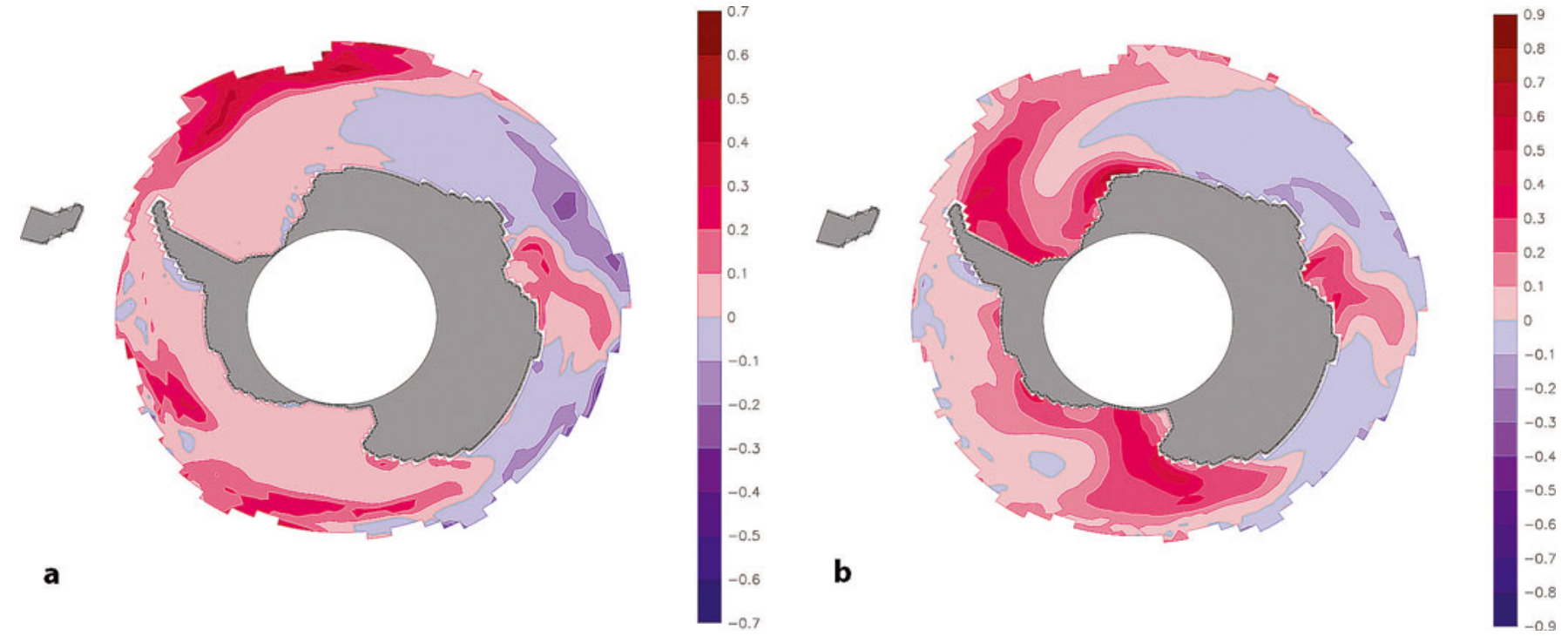

Fig. 5. Maximum monthly mean (August) difference of sea-ice concentration (a) and sea-ice thickness (b) between ISP and REF.


Fig. 6. Climatological annual mean of mixed-layer depth difference of ISP-REF (unit: $m$ ) in (a) Southern Hemisphere and (b) Northern Hemisphere.

stratification. The ISM also has direct effects on the Antarctic sea-ice cover. We find that some aspects of the sea-ice distribution and thickness are clearly improved by the addition of ISM.

The study shows that the ISM impact is not only local, but also global. As a response to the additional cold and fresh water mass source from Antarctic ISM, the MLD in the northern North Atlantic deepens by several tens of meters. An important next step will be to determine the physical mechanisms behind this teleconnection.

\section{ACKNOWLEDGEMENTS}

We are indebted to the Drakkar group for providing the ORCA2-LIM configuration, and in particular to J.-M. Molines for his assistance in setting up the model in Helsinki.

\section{REFERENCES}

Beckmann, A. and H. Goosse. 2003. A parameterization of ice shelf-ocean interaction for climate models. Ocean Model., 5(2), 157-170.

Beckmann, A., H.H. Hellmer and R. Timmermann. 1999. A numerical model of the Weddell Sea: large-scale circulation and water mass distribution. J. Geophys. Res., 104(C10), 23,375-23,392.

Drewry, D.J., ed. 1983. Antarctica: glaciological and geophysical folio. Cambridge, University of Cambridge. Scott Polar Research Institute.

Gladstone, R.M., G.R. Bigg and K.W. Nicholls. 2001. Iceberg trajectory modeling and meltwater injection in the Southern Ocean. J. Geophys. Res., 106(C9), 19,903-19,916.

Hellmer, H.H. 2004. Impact of Antarctic ice shelf basal melting on sea ice and deep ocean properties. Geophys. Res. Lett., 31(10), L10307. (10.1029/2004GL019506.) 
Large, W.G. and S.G. Yeager. 2004. Diurnal to decadal global forcing for ocean and sea-ice models: the data sets and flux climatologies. Boulder, CO, National Center for Atmospheric Research. (NCAR Tech. Note TN-460.)

Levitus, S. and 7 others. 1999. NOAA atlas NESDIS 18, World Ocean Database 1998. Vol. 1: introduction. Washington, DC, US Department of Commerce. National Oceanographic Data Center. CD-ROM.
Timmermann, R., A. Beckmann and H.H. Hellmer. 2001. The role of sea ice in the fresh-water budget of the Weddell Sea, Antarctica. Ann. Glaciol., 33, 419-424.

Timmermann, R., H. Goosse, G. Madec, T. Fichefet, C. Ethe and V. Dulière. 2005. On the representation of high latitude processes in the ORCA-LIM global coupled sea ice-ocean model. Ocean Model., 8(1-2), 175-201. 